\title{
Insight into food handlers' perceived barriers and motivators to perform food temperature control practices in Malaysian public schools
}

\author{
${ }^{1,3}$ Wong, S.Y.W., ${ }^{1}$ Izzah, A., ${ }^{1}$ Mahyudin, N.A., ${ }^{2}$ Ho, J.A. and ${ }^{1 * U n g k u ~ F a t i m a h, ~ U . Z . A . ~}$ \\ ${ }^{1}$ Faculty of Food Science and Technology, Universiti Putra Malaysia, 43400 UPM Serdang, Selangor, \\ Malaysia \\ ${ }^{2}$ Faculty of Economics and Management, Universiti Putra Malaysia, 43400 UPM Serdang, Selangor, \\ Malaysia \\ ${ }^{3}$ Faculty of Applied Sciences, UCSI University, Cheras, 56000 Kuala Lumpur, Malaysia
}

\begin{abstract}
Article history:
Received: 20 October 2019

Received in revised form: 24

November 2019

Accepted: 29 December

2019

Available Online: 14 January 2020
\end{abstract}

Keywords:

Food safety,

Temperature control,

Barriers,

Motivators

DOI:

https://doi.org/10.26656/fr.2017.4(3).347

\section{Introduction}

Food and waterborne disease is a significant public health threat worldwide. According to World Health Organization (WHO), every year, more than one-third of the population, especially in developing countries suffered from various health issues due to the consumption of contaminated food and water (World Health Organization, 2007). Certain groups, especially young children, are at a higher risk of developing foodborne disease due to their underdeveloped immune system (Prashanth and Indranil, 2016). In Malaysia, the majority of foodborne disease outbreaks occurred in schools, and the rapid increase of the cases reported in recent years had alarmed for further action (New et al. 2017). Food poisoning cases occurred in school have spiked from the year 2012 to 2015, with highest episodes reported in 2015 of an average of 8000 cases (Fuentes, 2015). In 2018, the number of food poisoning cases recorded an increase of $24 \%$, compared to the previous year (New Straits Times, 2019). This call for the need to look into ways to improve the food safety practices among school food handlers.

Previous studies highlighted temperature abuse as one of the risk factors of foodborne diseases (FaourKlingbeil et al., 2015; Smigic et al., 2016; Tóth et al., 2017). This risk factor is also evident in Malaysia, whereby besides improper food handling and poor personal hygiene, temperature abuse has been identified as one of the causative factors for foodborne outbreaks (Sharifa et al., 2013; Abdul-Mutalib et al., 2015). Deficiency of temperature control was clearly shown in a study by Lee et al. (2012), where end-point cooking temperatures were not consistently recorded, and cold foods were frequently found to be above the recommended $5^{\circ} \mathrm{C}$. In a study to assess food temperature and holding time among cafeterias in UiTM, Terengganu, it was found that three out of four cafeterias were not in compliance with temperature control guidelines, and food was found to be displayed at a tray line without proper holding equipment (Musa et al., 
2015).

Temperature control is crucial to prevent the growth of dangerous pathogens in food. The use of food thermometers is one of the recommended best practice for food safety. However, in a review study on eightyfive studies from the past 21 years, Feng and Bruhn (2019) concluded that compliance with thermometer use is still low. People commonly use the color of meat as an indicator of cooking adequacy (Lin, 2018). However, color does not truly reflect the internal temperature of food. In a study to determine the relationship between the end-point temperature, internal cooked color and juice color in ground beef patties, Hague et al. (1994) reported that the color of the patties looked similar between cooking temperatures of $66^{\circ} \mathrm{C}$ to $71^{\circ} \mathrm{C}$. In another study by Bergsma et al. (2007), it was reported that the color of poultry during cooking does not reflect on the survival of Campylobacter jejuni. Thus, measurement of the internal temperature of food is the most reliable method to determine food doneness (Feng and Bruhn, 2019).

In Malaysia, food handlers are generally trained to keep food out of the temperature danger zone in the compulsory food handler training course. However, in a study to assess the food safety knowledge, attitude and practices among food handlers at a university in Malaysia, it was reported that the food handlers had inadequate knowledge on the importance of avoiding the temperature danger zone of $5^{\circ} \mathrm{C}$ to $60^{\circ} \mathrm{C}$ during food handling (Abdullah Sani and Siow, 2014). In general, many food handlers were also not well equipped with the correct temperature control knowledge to prevent microbial growth, especially during cooking, cooling, defrosting, reheating and cold storage (Faour-Klingbeil et al., 2015; Webb and Morancie, 2015; Smigic et al., 2016).

The hot and humid climate in Malaysia is very supportive of the growth of foodborne bacteria in food. Inadequate heat treatment and foods prepared too early and kept at ambient temperature until served give rise to food safety risks (Abdul-Mutalib et al., 2015). This explains the persistent occurrence of foodborne outbreaks in recent years, despite various measures taken by the authorities. Salmonella made the headlines in 2018 whereby at least 83 infected cases and two deaths were reported after consuming laksa noodles in Kedah, Perak and Selangor. Besides unhygienic food preparation, it was identified that the temperature during cooking and reheating of the noodles was inadequate to prevent the growth of the pathogen (Asia One, 2018). Similarly, alarming levels of food poisoning cases in Perak was also attributed to temperature abuse. Malay
Mail (2018) reported that the main factor which led to poisoning among the cases is due to the improper handling of food, which was not kept at the correct temperature.

Safe food temperature and holding time were considered one of the most critical risk assessment in institutions (Musa et al., 2015). However, there were limited studies done in this critical area. Majority of the food safety studies in Malaysia assessed the general food safety Knowledge, Attitude, and Practices (KAP) of food handlers (Abdul-Mutalib et al., 2012; Norazmir et al., 2012; Abdullah Sani and Siow, 2014; Siau, 2015). Till date, only one study assessed the temperature control practice among four cafeterias in UiTM, Dungun, Terengganu (Musa et al., 2015). Due to the lack of information on temperature control practices among the study population, this study was conducted to gain an insight into the current temperature control practices, and identify the barriers and motivators to perform temperature control practices among school food handlers, using a qualitative method.

\section{Materials and methods}

\subsection{Study design}

This cross-sectional, qualitative study was conducted in Klang Valley, Malaysia. The qualitative data, collected in focus group discussions (FGD) was used to explore the current practices, barriers, and motivators of school food handlers to food temperature control. FGD is a well-established way of collecting qualitative data by engaging a small number of people in an informal group discussion, revolving on a particular topic. The dynamic quality of group interaction allows respondents to build upon the responses of one another and lead to a more elaborated input and discussion (Silverman, 2006).

\subsection{Sample and sampling site}

Seven FGD were carried out among 64 school food handlers with and without supervisory responsibilities. Participants were of heterogeneous groups. Participants were recruited using purposive sampling method based on the following inclusion criteria: food handlers above 18 years that are working in public-funded government schools and able to communicate in English, Bahasa Malaysia or Mandarin language. The participants were selected from a total of 26 schools consisting National school $(\mathrm{n}=13)$, National-type Chinese school $(\mathrm{n}=8)$ and National-type Tamil school $(\mathrm{n}=5)$. The study provided monetary incentive and free transportation to the food handlers in order to encourage participation. The FGDs were conducted in different locations at selected hotels in Klang Valley, Malaysia (i.e., Ampang, Bangi, Putrajaya, Klang, Shah Alam, Semenyih, 
Table 1. Key questions administered to FGDs in Klang Valley

\begin{tabular}{llc}
\hline $\begin{array}{l}\text { Topic } \\
\text { practices }\end{array}$ & How do you achieve the correct food temperature during cooking? & Temperature control practice \\
& $\begin{array}{l}\text { What are the current temperature control practices during the holding } \\
\text { of food? }\end{array}$ & $\begin{array}{c}\text { Thermometer use } \\
\text { Avoiding temperature danger } \\
\text { zone }\end{array}$ \\
\hline $\begin{array}{l}\text { Perceived } \\
\text { barriers }\end{array}$ & $\begin{array}{l}\text { What are the factors that make it difficult for you to use a thermometer } \\
\text { during cooking? }\end{array}$ & $\begin{array}{c}\text { Thermometer use } \\
\end{array}$ \\
& $\begin{array}{l}\text { What are the factors that make it difficult for you to use hot holding } \\
\text { equipment during holding? }\end{array}$ & Avoiding temperature danger \\
& zone
\end{tabular}

Kajang). Each FGD comprised of 6-10 food handlers from 3-4 different schools and lasted approximately 90 120 mins. Data were collected until data saturation.

\subsection{Data collection}

Every FGD was led by one moderator and one assistant moderator who acts as notes taker. The same moderator and assistant moderator were involved in all sessions. First, the purpose of the study and consent process was explained, followed by a simple questionnaire to collect participants' demographic information. Then, a short video clip of proper temperature control practice was played to ensure that participants have a similar understanding of proper temperature control. FGDs were then conducted following a script of semi-structured open-ended questions with probes. The script was developed through literature review and by obtaining feedback from food safety experts. Table 1 summarizes the key questions of the study. The discussions were recorded using audio devices with the consent of the participants.

\subsection{Data analysis}

For FGD data analysis, the audio recordings were transcribed into verbatim, and data-driven coding was done following the method by Campbell et al. (2013). From the verbatim, one researcher developed a list of thematic codes. Then, a second researcher independently coded approximately $25 \%$ of randomly selected data sets scripts using the list of thematic codes. In other studies, $20 \%$ of data set scripts (Meacham, 2016) has been recommended for independent coding by the second researcher. The results and Cohen's kappa were then compared, and any disagreements were resolved. The list of thematic codes was then improvised; with the collapse of similar themes and redefining some coding definitions. A second attempt for both researchers to code was made, and Cohen's kappa was recalculated. Upon satisfactory intercoder reliability, the improvised coding was used on the full script. The data were analyzed using ATLAS.ti 7 (Version 7.5.15, Scientific Software Development $\mathrm{GmbH}$, Berlin) qualitative data analysis software. Coding Analysis Toolkit (Texifter, LLC) was used to analyze inter-coder reliability. Cohen's kappa measure of 0.75 and above is considered excellent (Cicchetti, 2015).

\section{Results and discussion}

Canteen foodservice operations in national-funded schools in Malaysia consist of small-scale family businesses, where family members are often roped in to help run the foodservice operations. In many schools, family members of the canteen owner commonly hold a supervisory role in the canteen. Additional food handlers are recruited locally and from neighboring countries, especially Indonesia, to help in the operation. Each FGD comprised of participants of heterogeneous groups; with a diverse background, designation, and demographic profile. Such heterogeneous groups were able to produce more comprehensive input on the topic of discussion.

\subsection{Demographic characteristics}

Table 2 shows the participants' demographic characteristics. A total of 64 food handlers from three different school types (i.e., National school, Nationaltype Chinese School, and National-type Tamil school) participated in this study. The FGDs comprised of $14.1 \%$ canteen owners, $37.5 \%$ family members of owners, and $48.4 \%$ canteen operators. Majority of the participants were Malaysians (76.6\%), female $(70.3 \%)$, received formal education up to secondary school level $(67.2 \%)$, had received anti-typhoid vaccination $(92.2 \%)$ and attended the compulsory food handler training course (75\%). Surprisingly, even though it was made mandatory, some participants were not vaccinated against typhoid (7.8\%) and were not trained in safe food handling $(25.0 \%)$. 
Table 2. Demographic characteristics of focus group participants $(\mathrm{n}=64)$

\begin{tabular}{llc}
\hline Demographic characteristics & $\mathrm{n}(\%)$ \\
\hline \multirow{3}{*}{ School type } & National & $35(54.7)$ \\
& Chinese & $20(31.3)$ \\
& Tamil & $9(14.1)$ \\
\hline \multirow{2}{*}{ Designation } & Canteen owner & $9(14.1)$ \\
& Family member of the & $24(37.5)$ \\
& owner & $31(48.4)$ \\
\hline \multirow{2}{*}{ Country of origin } & Canteen operator & $49(76.6)$ \\
& Malaysia & $15(23.4)$ \\
\hline \multirow{2}{*}{ Gender } & Indonesia & $19(29.7)$ \\
& Male & $45(70.3)$ \\
\hline \multirow{4}{*}{ Highest qualification } & Female & $2(3.1)$ \\
& No formal education & $12(18.8)$ \\
& Primary & $43(67.2)$ \\
& Pre-U & $2(3.1)$ \\
Attended food handlers & Yes & $5(7.8)$ \\
\hline training course & No & $48(75.0)$ \\
\hline vaken anti-typhoid & Yes & $16(25.0)$ \\
\hline & No & $59(92.2)$ \\
& Diploma & $5(7.8)$ \\
\hline
\end{tabular}

3.2 Current temperature control practices during cooking

In this study, food handler's current practices on food temperature control were explored. For certain food products, especially processed food, the cooking instructions on the food packaging are followed to ensure sufficient cooking. A 44-year-old, female canteen owner stated the following:

"For certain food, let's say frozen food, there will be information on the packaging on the packaging, stating how long does it take to cook that product, definitely hot enough. Usually, when we fry certain food, there will be instructions at the packaging to teach us how to cook that product." (44-year-old, female canteen owner, Klang)

In a study to examine the influence of safe food handling labels on consumer preparation practices for meat, it was reported that $37 \%$ of respondents who had read the label reported changing their raw meat preparation methods accordingly. Women were also more likely than men to have read the label (Yang et al., 2000).

For other food that is freshly prepared, food handlers rely on their experience and visual indicators to determine whether food has been cooked adequately during cooking. Physical changes to the food in terms of appearance, color, taste, and the presence of boiling water bubbles indicate the doneness of food.
"We look at the color; we already know it [food] is cooked or not. If it is not cooked, the color is different. If it is cooked, is it different." (41- year old, female canteen owner, Klang)

"Through experience, by looking at the bubbles." (47 -year-old, male canteen owner, Ampang)

"For example depends on the foods itself, fish or chicken. For example, fried chicken is about 5 minutes." (50-year-old, female canteen operator, Bangi)

Some participants also revealed that they rely on their gut feelings to ensure that food is cooked to the correct temperature. The following quote reflects this practice:

"Depends on our feeling. We have been working for so long...feeling, feeling. Because we have been [cooking] for so many years." (44-year-old, female canteen owner, Klang)

Similar to findings of previous studies (Green and Selman, 2005; Santos et al., 2008), food handlers generally rely on their own experience and changes in the sensory characteristics of food to gauge if foods are cooked adequately. Up to $93 \%$ of consumers were reported to rely on visual indicators to determine the adequacy of cooking for meat product (Sampers et al., 2012). In a study to assess the survival of $C$. jejuni on chicken meat, Bergsma et al. (2007) highlighted that although fried chicken breast fillet appeared sufficiently cooked, there is a high probability of surviving C. jejuni cells in the meat after cooking. For burger, there is an only slight visual difference between semi- and wellcooked burger meat. Besides, relying solely on visual indicators also pose a possible problem as the cooking time could differ according to the thickness of the meat (Sampers et al. 2010).

The absence of thermometer-use during cooking highlight possible food safety concerns because cooking is a crucial factor in preventing foodborne diseases (Kennedy et al., 2011). Previous studies have highlighted the importance of thermometer-use, especially when cooking raw meat or poultry in order to achieve the recommended temperature (Green and Selman, 2005; Lelieveld et al., 2016; Feng and Bruhn, 2019). In a study by Phang and Bruhn (2011), it was reported that at least $30 \%$ of the respondents tend to undercook meat. When the meat is undercooked, microorganisms that survived the cooking process may start multiplying to high numbers when the condition is favorable to them again. Even though the required time-temperature combination varies depending on the food composition, volume of food, heat resistance and distribution of the microorganisms (Bermudez-Aguirre and Corradini, 
2012; de Jong et al., 2012), one of the biggest challenge faced in many food establishments was in ensuring an internal temperature of at least $75^{\circ} \mathrm{C}$ is achieved during cooking (Veiros et al., 2009).

\subsection{Current temperature control practices during hot holding}

Participants described that different methods were used during the holding of hot food, depending on the customer, type of food, student capacity, and financial capability of canteen contractors. Most of the canteen operators equip hot-holding equipment only for foods served to teachers. Hot holding equipment generally refers to equipment that is used to store or hold hot food at the correct temperature until being served. Examples include the commonly used bain-marie, food warmer, and holding cabinet. However, the majority of the participants ( 25 out of 26 schools) do not use bain-marie for foods sold to students. Due to the high number of students per school (ranging between hundreds to two thousand), foods prepared for students are usually prepacked into individual serving and left at ambient temperature until sold. This practice is to reduce the waiting time of students during their short break.

For foods served to students, time control of food left at ambient temperature is a standard method employed. Food that is held at ambient temperature for some time will usually be subsequently reheated. However, there is a discrepancy among respondents on the number of hours that cooked food can be left at room temperature, ranging between 4 to 6 hours:

"Oh, temperature control, because we have been to the course [food safety training] by Ministry, He said we do not need to use the temperature control machine to control the temperature. They just said ... we must reheat the cooked food within 4 hours; then we can sell it... If not finish for the morning session, we reheat again [for afternoon session]." (44-year-old, female canteen owner, Klang)

"There is this 5-hour rule...." (47-year-old, male canteen owner, Ampang)

"Aah...6 hours. Then it still can be eaten again. Reheat first, slow fire." (31-year-old, female canteen operator, Semenyih)

In this study, the discrepancy in food handlers' knowledge and understanding among participants highlight a possibility of temperature abuse and inefficiency of time-control during holding. Public schools in Malaysia operate either in one-session (halfday; with one tea break) or two sessions (full day; with two tea breaks), depending on the number of students enrolled in the school. As food handling and cooking process may begin as early as $5.00 \mathrm{am}$, and the last food may be served at $3.30 \mathrm{pm}$, food must be kept at the correct temperature to reduce the growth of microorganisms in food. This requirement is especially so as Malaysia's hot and humid climate all year long is very conducive for the growth of microorganisms (Abdul -Mutalib et al., 2015). Regular cooking is only able to destroy the vegetative cells, but not spore-forming pathogens. One such example is the heat-resistant spores of Bacillus cereus. The improper holding of rice-based or starchy food at ambient temperature allows spore germination and the growth of $B$. cereus, followed by the production of toxins in the food (Tewari and Abdullah, 2015). This reinforces the importance of keeping food at the correct temperature during holding.

It is a requirement to ensure that a food warmer maintains a temperature of food above $60^{\circ} \mathrm{C}$, where the food is to be served hot (Food Act 1983 [ACT 281] and Regulations, 2013). During reheating, food generally needs to be reheated to a minimum temperature of $73^{\circ} \mathrm{C}$ (Green and Selman, 2005). If hot holding equipment is not available, they can serve food at ambient temperature for not more than four hours before consumption (Salleh et al., 2017). The use of such time control is also widely emphasized in the compulsory Malaysian food handler training course. The World Health Organization (WHO) recommended that in the absence of proper refrigeration facilities, food should be cooked in small amounts followed by immediate consumption to minimize leftovers (WHO, 2008).

Meanwhile, for a specific food, such as rice and soup, participants reported that they used different holding methods. For cooked rice, they are commonly kept warm using insulated plastic containers until being served. Nevertheless, the temperature of rice in the insulated containers over an extended period is not known. For soups (i.e., clear broth, soups or curry), they are continuously kept warm over a low flame on the stove throughout the holding period. The following quote reflects this practice:

"Just like when we are cooking soup ah, curry soup ah, clear soup or that... soup oh, we let it boil... we do not turn off the fire (referring to flame on a gas stove) at all. A small fire is used to maintain the temperature. Ah... do not off the fire. Cook in the morning, kept till evening." (58-year-old, female canteen owner, Klang)

\subsection{Perceived barriers to using thermometer during cooking}


Five themes emerged from the FGDs about perceived barriers that hinder food handlers from using a food thermometer: time constraint, inconvenience, inadequate knowledge, lack of resources, and not a requirement, as shown in Figure 1.

In this study, time constraint and inconvenience were

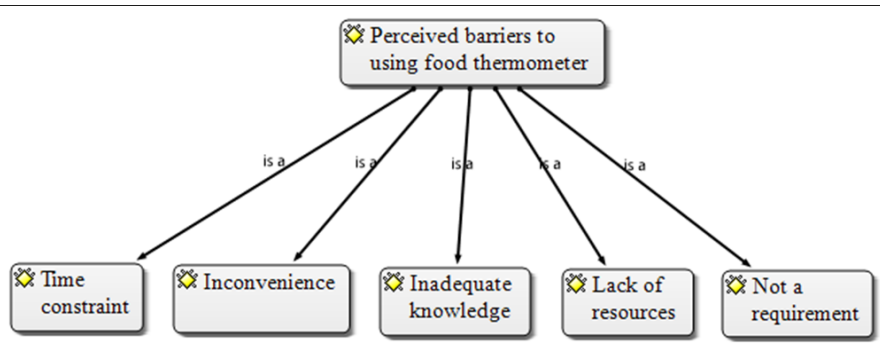

Figure 1. Themes emerged for perceived barriers to using thermometer during cooking.

the most frequently mentioned barrier to using a food thermometer. This is reflected in the following quotes:

"Time is already not enough for us, still expect us to check the food temperature..." (53-year-old, female, family member of canteen owner, Klang)

"There is no problem when the amount of food is small. However, if the amount is big, there is a bit of a problem. When there is a lot, it becomes a little troublesome." (32-year-old, male, family member of canteen owner, Putrajaya)

Many participants perceived that the fire-fighting mode of school foodservice operation does not allow time for food handlers to adopt the use of a thermometer. Participants also highlighted that thermometer use would take a lot of their time to be practiced in daily work routine. This finding was similar to the previous study by Howells et al. (2008), where food handlers perceived that thermometer use during cooking would be too timeconsuming and additional staffs are needed to carry out the practice. The inconvenience of using thermometer has also been highlighted in similar studies because the requirement to sanitize thermometer between each use will be too troublesome (Green and Selman, 2005; York et al., 2009).

Thus, previous studies have called foodservice managers to improve food handlers' productivity by organizing workflow at foodservice operations (Strohbehn et al., 2014; Arendt et al., 2015). This effort is essential to allow food handlers to perform the necessary food safety practices effectively without compromising the quality of day-to-day tasks at their workplace.

During FGDs, participants also exhibited a lack of knowledge and understanding of the importance of using food thermometer during cooking. Some could not relate temperature control to the survival or growth of microorganisms in food. Whereas others do not have the knowledge nor the skill to use a food thermometer.

"The thermometer can only be used to check whether the food is hot or not. You cannot check whether it has poison or germs, right? Are there any germs? The flies that land on the food also bring germs. No matter how hot you cook the food also useless, once eaten by children will cause stomach pain. That is because children only have little antibody. You cannot guarantee the food has poison or not, or germs or not. So what is the use of the thermometer then?" (50-year old, female canteen owner, Klang)

"Need to know how to use it [thermometer] loh. We do not know how to use it." (58-year-old, female canteen owner, Klang)

"Difficult... don't know because haven't done it before [using food thermometer]." (29-year-old, female supervisor, Putrajaya)

Food handlers in Malaysia mostly acquire food safety knowledge through the mandatory food handler training course, which generally covers aspects of food hygiene and safety. The course emphasizes the importance of avoiding temperature danger zone during holding and relying on senses to evaluate if food is sufficiently cooked. The lack of knowledge on the use of food thermometer could be due to the limited scope covered in the training and lack of hands-on training on the use of thermometer. Other studies have also reported that inadequacy of knowledge is an important barrier (Santos et al., 2008; Siebert et al., 2014; Siau, 2015). Food handlers exhibit lack of knowledge on temperature control especially related to the recommended endpoint temperature, the method to use the thermometer and thermometer use for specific food groups (Strohbehn et al., 2014; Arendt et al., 2015). Many food handlers were unaware that food should be cooked properly according to recommended temperature (Green and Selman, 2005; Abdul-Mutalib et al., 2012; Arendt et al., 2015; Tóth et al., 2017). Only $40 \%$ of food handlers can identify the recommended internal temperature for cooking of poultry and ground beef (Jianu and Chiş, 2012; Feng and Bruhn, 2019).

In addition, participants also highlighted that the lack of resources, i.e. food thermometer, hinder them from measuring the temperature of food during cooking. Participants think that the responsibility lies with their superior and they are willing to carry out the practice as long as thermometers are provided in the premise.

"Boss did not buy thermometer..." (31-year old, female food operator, Semenyih) 
“...This is not difficult, it's just the cost... it's expensive. Think that this is easy to do, it depends on the boss lah...If boss wants to buy, we will do it [use food thermometer]" (41-year-old, female, family member of canteen owner, Klang)

Themes emerged in this study were generally in agreement with a study by Howells et al. (2008), where it was reported that time constraints, inconvenience, inadequate training, and resources were barriers to thermometer use. An additional barrier, identified in this study was that thermometer use is not a requirement. The quote for 'not a requirement' is reflected here:

"We have not received instructions from the Ministry to use a thermometer. So we are not using any." (44-year old, female canteen owner, Klang)

Food handlers were generally not enthusiastic about using food thermometer during cooking as there was no enforcement mandating them to do it. Previous studies have shown that the lack of enforcement and regulation on food safety can negatively affect safe food handling practices among food handlers (Arendt et al., 2015; Thaivalappil et al., 2018). Therefore, it is timely for the relevant authorities to mandate the use of thermometer in school foodservice operations in Malaysia. Canteen owners will be obligated to comply and ensure a sufficient supply of thermometers once it becomes a legal requirement. Food handlers will be able to carry out temperature control practice with sufficient resources provided at schools.

The identified barriers need to be addressed if food temperature control practices are to be improved. Food handlers would be more likely to improve their food safety practices if they perceive fewer barriers to perform them. In addition, Malaysia which comprises of the multi -ethnic population may also vary in their cooking style and practices. Feng and Bruhn (2019) found that it is more challenging to persuade food handlers who cook ethnic cuisine about the benefit of thermometer-use. This is because of the variation of the cooking style used and the practice not being part of their tradition.

\subsection{Perceived barriers to using the hot holding equipment}

Two themes emerged from the FGDs about perceived barriers that hinder them from using hot holding equipment: lack of resources and uncertainty of contract renewal (Figure 2). Many food handlers strongly feel that the lack of resources hinders them from using hot holding equipment. The theme includes a lack of financial capability to purchase the necessary equipment due to the low-profit-margin in school foodservice operations, and the lack of space at school canteens.

"... because you have to know that we work under the school only earn little profit, the price of foods sold are also squeezed until very cheap... ah... I feel if you are the employer, every item also need to prepare such equipment... the biggest problem is money. How much money do you need to use to get such equipment? How much capital do you need to get such equipment? Before profiting, already use up so much money. Definitely, no one wants to be school canteen operator anymore!" (44year-old, female canteen owner, Klang)

"Canteen is so small, how to put [the hot holding equipment]? The equipment is so big, more or less already occupied half of the space in the canteen". (52year-old, male canteen operator, Klang)

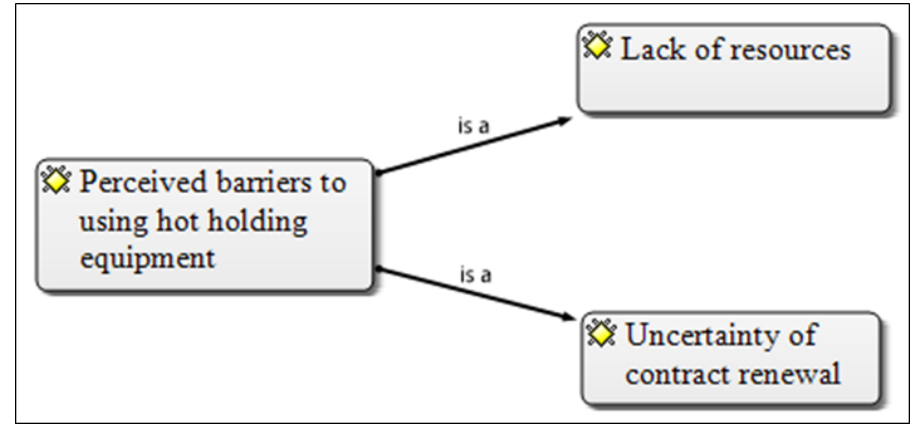

Figure 2. Themes emerged for perceived barriers to using hot holding equipment.

The theme 'lack of resources' was similar to findings from previous studies (Green and Selman, 2005; Arendt et al., 2015). Inadequate resources and insufficient food safety education tend to affect safe holding practice among food handlers. Management and authorities play a crucial role to provide the relevant resources for food handlers to perform the safe holding practice.

Another important theme that emerged is the uncertainty of school canteen contract renewal, as reflected in the following quotes:

"Some things [referring to purchase of equipments] are applicable for the restaurant. A permanent restaurant can. We do not dare to buy things [equipment]". (47-year-old, male canteen owner, Ampang)

"Where do you want to shift [the equipment] to? If they [school] do not want to replace, do not want to buy from you, where do you want to shift it [hot holding equipment] to?" (28-year-old, male canteen owner, Ampang)

The participants are hesitant to invest in expensive equipment for fear that their canteen contract is discontinued. They generally feel that such practice is more suitable to be implemented in restaurants. In 
Malaysia, successful canteen contractor applicants have a contract period of two years for selling food and drinks at a particular school premise. After two years, schools reserve the right to renew or terminate the service, and another round of canteen tender process may be needed. Because of the uncertainty, owners of school canteen become hesitant to invest in expensive hot holding equipment. They also questioned the fate of the equipment if schools do not renew their canteen contract.

\subsection{Motivators to perform proper temperature control} practice

Five themes emerged from the FGDs about motivators to perform overall proper temperature control practices (i.e., thermometer use and avoiding temperature danger zone during holding). These include the availability of resources, law and enforcement, intrinsic motivation, customer satisfaction, and knowledge and training (Figure 3).

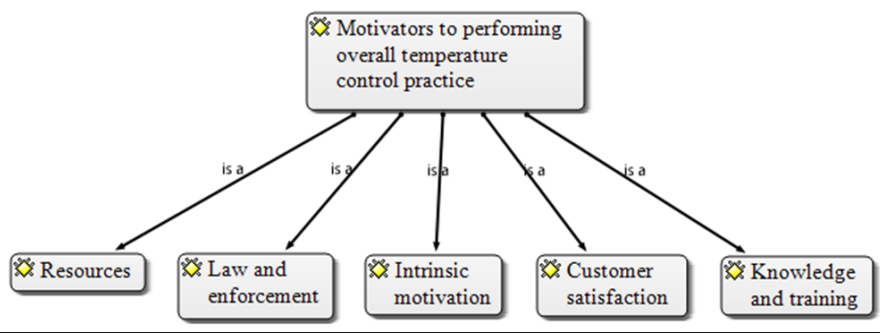

Figure 3. Themes emerged for motivators of school food handlers to perform overall temperature control practice $(\mathrm{n}=64)$

Food handlers stated that the availability of equipment for temperature control practice, such as a thermometer and hot holding equipment are crucial to motivate food handlers to perform temperature control practices. Having enough and adequate resources is an essential motivator for food handlers to perform proper temperature control practice during cooking and holding. This is shown in the following quotes:

"As long they will supply [provide the resources, i.e., thermometer and hot holding equipment]." (39-year-old, female food operator, Klang)

"If there is [adequate resources], then it is convenient." (58-year-old, male canteen owner, Semenyih)

"I think if they force, we need to do this [perform temperature control practices]. Moreover, they provide the thing free of charge [provide complimentary thermometer]. I think it is for our own good to take care of the food temperature, so I think ok lah, can follow lah." (44-year-old, female canteen owner, Klang)

Having a properly maintained equipment for holding practice, an adequate number of thermometers and a temperature log to record food temperatures are example of resources and facilities that can facilitate food handlers perform proper temperature control practice (Green and Selman, 2005; Howells et al., 2008; Arendt et al., 2015; Feng and Bruhn, 2019). Several studies indicated the role of managers to provide the adequate resources and facilities so that food handlers can perform according to the food safety guidelines (Howells et al., 2008; Arendt et al., 2015).

Participants also mentioned that they are more likely to perform the task if it is a requirement under the law. Enforcement with stringent monitoring, such as the use of closed-circuit television (CCTV) surveillance will also drive them to perform the necessary practices.

"... regarding the thermometer, need to do, if there is a law that says need to do (perform temperature control), then need to do it..." (33-year-old, female, family member of canteen owner, Putrajaya)

"Nothing, there is nothing that drives you to do it [perform the temperature control practice]. Like I say just now, motivation... the motivation is you must have $C C T V^{\prime \prime}$. (37-year-old, female, family member of canteen owner, Ampang)

The requirement for thermometer use has not been made mandatory by the authorities. Even though timecontrol during holding is a useful way to avoid excessive multiplication of microorganisms at ambient temperature, it does not give assurance that the food is sufficiently cooked before holding. Improperly cooked food is well-known to be one of the critical risk factors for foodborne disease. Prior studies have demonstrated that inconsistency in the enforcement of the food safety laws, regulation and procedures can generate negative food safety behaviors among food handlers (Arendt et al., 2015; Thaivalappil et al., 2018).

Intrinsic motivation has also been identified as an essential motivator for food handlers to perform temperature control practices. Participants in FGDs mentioned that the feeling of confidence is the intrinsic motivator that drives them to perform temperature control practices.

"... so, we feel more confident. Confirm la that this is the safe temperature and so on." (32-year-old, male, family member of canteen owner, Putrajaya)

Ryan and Deci (2000) define intrinsic motivation as "doing of an activity for its inherent satisfactions rather than for some separable consequences." When intrinsically motivated, a person is driven to act for the fun or challenge involved rather than because of external pressures or reward" (Oudeyer and Kaplan, 2008). 
Simply put, intrinsic motivation is an act of individually driven by internal or personal rewards. This motivator is similar to the findings of previous studies (Arendt et al., 2015; Thaivalappil et al., 2018). For example, food handlers claimed that they enjoyed following the proper food safety practice as they gained satisfaction from doing the right thing (Arendt et al., 2015). Nevertheless, the natural tendencies of intrinsic motivation can be easily disrupted by many factors. For example, extrinsic rewards, threats, deadlines and directives tend to diminish intrinsic motivation. Thus, supportive conditions that allow people to develop a feeling of autonomy are essential to ensure the maintenance and continuity of intrinsic motivation (Ryan and Deci, 2000).

Another theme that emerged through FGDs is customer satisfaction. Food handlers are more motivated to perform the necessary tasks when receiving compliments from satisfied teachers and students at school canteens. This is reflected in the following quote:

"Satisfaction from students and teachers is the important thing..." (58-year-old, female canteen operator, Kajang

Feeling responsible towards the customer health and satisfaction can motivate food handlers to perform appropriate temperatures control practice to ensure the cooked food safe to consume by their customer. When food handlers have empathy towards their customer by putting themselves in customers' shoes, this will encourage food handlers to handle food safely. School authorities should support a food safety work culture that put the customers' safety and satisfaction as the priority since it is the food handlers' motivator to perform food safety practice (Arendt et al., 2015).

Besides, having sufficient knowledge on temperature control has also been identified as a motivator for food handlers to perform the practices. Provision of knowledge or training have been widely reported in previous studies to be able to motivate food handlers to perform correct food safety practices (Lee et al., 2012; Thaivalappil et al., 2018).

"We need to have some knowledge to use that thing [thermometer]. So, if we have it provided by the school or buy ourselves, it is a second thing. If they [school] give it, much better. We can buy [thermometer], but we need to know how to use it." (56-year-old, male canteen owner, Semenyih)

\section{Conclusion}

This research shed some light on the current food temperature control practices in Malaysian public schools. The views gathered from this study provide a realistic picture of the thoughts and current situation in which these food handlers work. Although the perceived barriers and motivators are generally in agreement with other studies, this research has highlighted new barriers: not a mandatory requirement and uncertainty of business contract renewal. It is suggested that thermometer-use should be made mandatory with stringent enforcement. This is only possible if food handlers are trained adequately on how and when to use a food thermometer. As time pressure was identified as an important barrier, training should focus on eliminating food handlers' misconception of time. Food handlers ought to be taught that checking the endpoint cooking temperature only takes 30 seconds. In terms of the holding of food, it is recommended that public schools be properly equipped with adequate hot holding equipment. Such equipment can then be rented to school canteen operators as they are operating on a contractual basis. This arrangement can ensure a continuity of the temperature control practices, regardless of which canteen contractor that manages to secure the tender. Findings from this study provide information for school canteen managers, school administration, and relevant authorities to improve and effectively implement proper temperature control practice at public school canteens. Addressing some of the barriers identified in this study will enable better success in enforcing the required food safety practice.

\section{Conflict of Interest}

No known conflicts of interest in this study.

\section{Acknowledgments}

The research work was funded by the University research grant GP-IPS (9474500). Ethics approval was obtained from the Ethics Committee for Research Involving Human Subject, Universiti Putra Malaysia. Special thanks to the Ministry of Education Malaysia, State Education Department, and school authorities for allowing this study to be conducted in schools. The authors are also thankful to all the participants for participating in the study.

\section{References}

Abdullah Sani, N. and Siow, O.N. (2014). Knowledge, attitudes and practices of food handlers on food safety in food service operations at the Universiti Kebangsaan Malaysia. Food Control, 37(1), 210 217. https://doi.org/10.1016/j.foodcont.2013.09.036

Abdul-Mutalib, N.A., Abdul-Rashid, M.F., Mustafa, S., Amin-Nordin, S., Hamat, R.A. and Osman, M. (2012). Knowledge, attitude and practices regarding 
food hygiene and sanitation of food handlers in Kuala Pilah, Malaysia. Food Control, 27(2), 289293. https://doi.org/10.1016/j.foodcont.2012.04.001

Abdul-Mutalib, N.A., Syafinaz, A.N., Sakai, K. and Shirai, Y. (2015). An overview of foodborne illness and food safety in Malaysia. International Food Research Journal, 22(3), 896-901.

Arendt, S.W., Strohbehn, C. and Jun, J. (2015). Motivators and barriers to safe food practices: Observation and interview. Food Protection Trends, 35(5), 365-376.

Asia One. (2018). Laksa poisoning in Malaysia: Noodles found to contain salmonella bacteria. Retrieved on October 8, 2019 from Asia One Website: https:// www.asiaone.com/malaysia/laksa-poisoningmalaysia-noodles-found-contain-salmonella-bacteria

Bergsma, N.J., Fisher, A.R.H., van Asselt, E.D., Zwietering, M.H. and de Jong, A.E.I. (2007). Consumer food preparation and its implication for survival of Campylobacter jejuni on chicken. British Food Journal, 109(7), 548-561. https:// doi.org/10.1108/00070700710761536

Bermudez-Aguirre, D. and Corradini, M.G. (2012). Inactivation kinetics of Salmonella spp. under thermal and emerging treatments: A review. Food Research International, 45(2), 700-712. https:// doi.org/10.1016/j.foodres.2011.05.040

Campbell, J.L., Quincy, C., Osserman, J. and Pedersen, O K. (2013). Coding In-depth Semistructured Interviews: Problems of Unitization and Intercoder Reliability and Agreement. Sociological Methods and Research, 42(3), 294-320. https:// doi.org/10.1177/0049124113500475

Cicchetti, D.V. (2015). Guidelines, Criteria, and Rules of Thumb for Evaluating Normed and Standardized Assessment Instrument in Psychology. Psychological Assessment, 6(4), 284-290. https:// doi.org/10.1037/1040-3590.6.4.284

de Jong, A.E.I., van Asselt, E.D., Zwietering, M.H., Nauta, M.J. and De Jonge, R. (2012). Extreme heat resistance of foodborne pathogens Campylobacter jejuni, Escherichia coli, and Salmonella Typhimurium on chicken breast fillet during cooking. International Journal of Microbiology, 2012, 1-10. https://doi.org/10.1155/2012/196841

Faour-Klingbeil, D., Kuri, V. and Todd, E. (2015). Investigating a link of two different types of food business management to the food safety knowledge, attitudes and practices of food handlers in Beirut, Lebanon. Food Control, 55, 166-175. https:// doi.org/10.1016/j.foodcont.2015.02.045

Feng, Y. and Bruhn, C.M. (2019). Motivators and barriers to cooking and refrigerator thermometer use among consumers and food workers: a review. Journal of Food Protection, 82(1), 128-150. https:// doi.org/10.4315/0362-028X.JFP-18-245

Food Act 1983 [ACT 281] and Regulations (2013). Food Hygiene Regulations 2009. Kuala Lumpur: International Law Book Services.

Fuentes, S. (2015). Calls for Government Action on Food Poisoning. Retrieved on May 29, 2019 from Free Malaysia Today Website: http:// www.freemalaysiatoday.com/category/ nation/2015/04/07/cap-calls-for-govt-action-on-food -poisoning/

Green, L.R. and Selman, C. (2005). Factors impacting food workers' and managers' safe food preparation practices: A qualitative study. Food Protection Trends, 25(12), 981-990.

Hague, W.A., Warren, K.E., Hunt, M.C., Kropf, D.H., Kastner, C.L., Stroda, S.L. and Johnson, D.E. (1994). End-point temperature, internal cooked color, and expressible juice color relationships in ground beef patties. Journal of Food Science, 59(3), 465-470. https://doi.org/10.1111/j.13652621.1994.tb05539.x

Howells, A.D., Roberts, K.R., Shanklin, C.W., Pilling, V.K., Brannon, L.A. and Barrett, B.B. (2008). Restaurant employees' perceptions of barriers to three food safety practices. Journal of the American Dietetic Association, 108(8), 1345-1349. https:// doi.org/10.1016/j.jada.2008.05.010

Jianu, C. and Chiş, C. (2012). Study on the hygiene knowledge of food handlers working in small and medium-sized companies in western Romania. Food Control, 26(1), 151-156. https://doi.org/10.1016/ j.foodcont.2012.01.023

Kennedy, J., Gibney, S., Nolan, A., O'Brien, S., McMahon, M.A.S., McDowell, D., Fanning, S. and Wall., P.G. (2011). Identification of critical points during domestic food preparation: an observational study. British Food Journal, 113(6-7), 766-783. https://doi.org/10.1108/00070701111140106

Lee, H.Y., Chik, W.N.W., Bakar, F.A., Saari, N. and Mahyudin, N.A. (2012). Sanitation Practices among Food Handlers in a Military Food Service Institution, Malaysia. Food and Nutrition Sciences, 3(11), 15611566. https://doi.org/10.4236/fns.2012.311204

Lelieveld, H., Holah, J. and Gabric, D. (2016). Handbook of hygiene control in the food industry. $2^{\text {nd }}$ ed. UK: Woodhead Publishing Limited.

Lin, C.-T.J. (2018). Self-reported methods used to judge when a hamburger is ready at-home in a sample of U.S. adults. Food Control, 91, 181-184. https:// 
doi.org/10.1016/j.foodcont.2018.03.042

Malay Mail. (2018). These are the main culprits behind Perak food poisoning cases, says state exco. Retrieved on October 8, 2019 from New Straits Times Website: https://www.malaymail.com/news/ malaysia/2018/10/11/these-are-the-main-culpritsbehind-perak-food-poisoning-cases-says-stateex/1681818

Meacham, S. (2016). Peer relationships and internally persuasive discourse. Learning, Culture and Social Interaction, 9, 95-104. https://doi.org/10.1016/ j.lcsi.2016.02.004

Musa, M., Khalid, K. and Anuar, J. (2015). Assessment of Temperature and Food Holding Time among Cafeterias in UiTM Dungun Terengganu. Journal of Applied Environmental and Biological Sciences, 5 (6S), 21-27.

New Straits Times (2019). Food poisoning cases up by 24 pc last year. Retrieved on October 8, 2019 from New Straits Times Website: https:// www.nst.com.my/news/nation/2019/07/504036/food -poisoning-cases-24pc-last-year

New, C.Y., Ubong, A., Premarathne, J.M.K.J.K., Thung, T.Y., Lee, E., Chang, W.S., Loo, Y.Y., Kwan, S.Y.,Tan, C.W., Kuan, C.H. and Son, R. (2017). Microbiological food safety in Malaysia from the academician's perspective. Food Research, 1(6), 183 - 202. https://doi.org/10.26656/fr.2017.6.013

Norazmir, M.N., Hasyimah, M.A.N., Shafurah, A.S., Sabariah, B.S., Ajau, D. and Norazlanshah, H. (2012). Knowledge and Practices on Food Safety among Secondary School Students in Johor Bahru, Johor, Malaysia. Pakistan Journal of Nutrition, 11 (2), 110-115. https://doi.org/10.3923/ pjn.2012.110.115

Oudeyer, P.-Y. and Kaplan, F. (2008). How can we define intrinsic motivation, presented at Proceedings of the $8^{\text {th }}$ International Conference on Epigenetic Robotics: Modeling Cognitive Development in Robotic System, Brighton, UK, p. 93-101. Lund: LUCS.

Phang, H.S. and Bruhn, C. (2011). Burger preparation: what consumers say and do in the home. Journal of Food Protection, 74(10), 1708-1716. https:// doi.org/10.4315/0362-028X.JFP-10-417

Prashanth, M. and Indranil, C. (2016). Food Poisoning: Illness Ranges from Relatively Mild Through to Life Threatening. Journal of Medical and Health Sciences, 5(4), 1-19.

Ryan, R.M. and Deci, E.L. (2000). Self-determination theory and the facilitation of intrinsic motivation, social development, and well-being. American $\begin{aligned} & \text { Psychologist, } \\ & \text { doi.org/10.1037/0003-066X.55.1.68 }\end{aligned}$

https://

Salleh, W., Lani, M.N., Zawiah, W. and Zin, W. (2017). $A$ review on incidences of foodborne diseases and interventions for a better national food safety system in Malaysia. Malaysian Applied Biology, 46(3), 1-7.

Sampers, I., Berkvens, D., Jacxsens, L., Ciocci, M.C., Dumoulin, A. and Uyttendaele, M. (2012). Survey of Belgian consumption patterns and consumer behavior of poultry meat to provide insight in risk factors for campylobacteriosis. Food Control, 26(2), 293-299.

Sampers, I., Habib, I., De Zutter, L., Dumoulin, A. and Uyttendaele, M. (2010). Survival of Campylobacter spp. in poultry meat preparations subjected to freezing, refrigeration, minor salt concentration, and heat treatment. International Journal of Food Microbiology, 137(2-3), 147-153. https:// doi.org/10.1016/j.jifoodmicro.2009.11.013

Santos, M.-J., Nogueira, J.R., Patarata, L. and Mayan, O. (2008). Knowledge levels of food handlers in Portuguese school canteens and their self-reported behavior towards food safety. International Journal of Environmental Health Research, 18(6), 387-401. https://doi.org/10.1080/09603120802100212

Sharifa Ezat, W.P., Netty, D. and Sangaran, G. (2013). Paper review of factors, surveillance and burden of foodborne disease outbreak in Malaysia. Malaysian Journal of Public Health Medicine, 13(2), 1-7.

Siau, M.F. (2015). Food court hygiene assessment and food safety knowledge, attitudes, and practices of food handlers in Putrajaya. International Food Research Journal, 22(5), 1843-1854.

Siebert, M.M., Perry, C., O’Connell, L., Albrecht, J., Stenger, K. and Vlasin-Marty, K. (2014). A mixed methods approach to investigating food safety behavior in a sample of Native American and Hispanic caregivers of young children. Journal of Food Research, 3(5), 59. https://doi.org/10.5539/ jfr.v3n5p59

Silverman, D. (2006). Qualitative Research: Theory, Method and Practice. $2^{\text {nd }}$ ed. London: SAGE Publications Ltd.

Smigic, N., Djekic, I., Martins, M.L., Rocha, A., Sidiropoulou, N. and Kalogianni, E.P. (2016). The level of food safety knowledge in food establishments in three European countries. Food Control, 63, 187-194. https://doi.org/10.1016/ j.foodcont.2015.11.017

Strohbehn, C., Shelley, M., Arendt, S., Correia, A.P., Meyer, J., Abidin, U.F.U.Z. and Jun, J. (2014). Retail foodservice employees' perceptions of barriers and 
motivational factors that influence the performance of safe food handling behaviors. Food Protection Trends, 34(3), 139-150.

Tewari, A. and Abdullah, S. (2015). Bacillus cereus food poisoning: International and Indian perspective. Journal of Food Science and Technology, 52(5), 2500-2511. https://doi.org/10.1007/s13197-014$1344-4$

Thaivalappil, A., Waddell, L., Greig, J., Meldrum, R. and Young, I. (2018). A systematic review and thematic synthesis of qualitative research studies on factors affecting safe food handling at retail and foodservice. Food Control, 89, 97-107. https:// doi.org/10.1016/j.foodcont.2018.01.028

Tóth, A.J., Koller, Z., Illés, C.B. and Bittsánszky, A. (2017). Development of conscious food handling in Hungarian school cafeterias. Food Control, 73(Part B), 644-649. https://doi.org/10.1016/ j.foodcont.2016.09.011

Veiros, M.B., Proença, R.P.C., Santos, M.C.T., KentSmith, L. and Rocha, A. (2009). Food safety practices in a Portuguese canteen. Food Control, 20 (10), 936-941. https://doi.org/10.1016/ j.foodcont.2009.02.002

Webb, M. and Morancie, A. (2015). Food safety knowledge of foodservice workers at a university campus by education level, experience, and food safety training. Food Control, 50, 259-264. https:// doi.org/10.1016/j.foodcont.2014.09.002

World Health Organization (WHO). (2007). Food safety and food-borne illness. Fact sheet No. 23. Retrieved on May 6, 2019 from WHO Website: http:// wwwwho.int/mediacentre/factsheets/fs237/en/.

World Health Organization (WHO). (2008). Foodborne Disease Outbreak. Guidelines for Investigation and Control. Retrieved on May 6, 2019 from WHO Website: http://www.who.int/foodsafety/ publications/foodborne_disease/Annex_7.pdf.

Yang, S., Angulo, F.J. and Altekruse, S.F. (2000). Evaluation of safe food-handling instructions on raw meat and poultry products. Journal of Food Protection, 63(10), 1321-1325. https:// doi.org/10.4315/0362-028X-63.10.1321

York, V., Brannon, L., Shanklin, C., Roberts, K., Howells, A. and Barrett, E. (2009). Foodservice employees benefit from interventions targeting barriers to food safety. Journal of the American Dietetic Association, 109(9), 1576-1581. https:// doi.org/10.1016/j.jada.2009.06.370 